\title{
Does critical illness cause reversible Cushing's like syndrome? A case study of two case reports and review of the literature
}

\author{
M. M. Brzozowska* and P. M. Davoren \\ Gold Coast Hospital, Southport 4215, Australia.
}

Accepted 27 February, 2012

\begin{abstract}
An activation of the hypothalamic-pituitary-adrenal axis (HPA) and elevated cortisol levels are common during critical illness. Clinically evident Cushing's syndrome, triggered by life threatening illness, has not been previously reported. We describe two patients with adrenocorticotropic hormone (ACTH)dependent Cushing's syndrome, which developed during the life threatening illness and later spontaneously remitted. The impact of the acute and prolonged phase of critical-illness on the function of HPA axis with its complex neuroimmunoendocrine dynamics has been reviewed.
\end{abstract}

Key words: Adrenocorticotropic hormone (ACTH)-dependent Cushing's syndrome, hypothalamic-pituitaryadrenal axis, critical illness.

\section{INTRODUCTION}

The release of cortisol in both acute and chronic phases of critical illness is essential for cardiovascular, metabolic and immunologic homeostasis. In addition, cortisol suppresses the endogenous inflammatory response, protecting the acutely ill patient against the overresponse of this system. Cortisol also improves the haemodynamic status of the stressed individual by inducing fluid retention and by its enhanced inotropic and vasopressor response to catecholamines (Frank and Van den Berghe, 2004).

The activated stress response system results in alteration in cardiovascular function, intermediary metabolism and immune mediated inflammation (Van den Berghe et al., 1998). In general, the degree of activation of hypothalamic-pituitary-adrenal (HPA) axis is proportional to the stress (Annane et al., 2000). The increased cortisol response to critical illness however does not usually result in clinical evidence of Cushing's syndrome. We report two patients who manifested evidence of glucocorticoid excess in response to the prolonged critical illness.

${ }^{\star}$ Corresponding author. E-mail: mbrzozowska@hotmail.com. Tel: (+61) 292958240 . Fax: (+61)2 92958241.

\section{CASE REPORT}

\section{Case 1}

A 56-year-old woman previously unknown to have diabetes was brought to the hospital severely ill. She had been unwell for one year prior to the presentation with polyuria, polydipsia and weight loss. Her weight was 38.0 $\mathrm{kg}$ at presentation. She had diabetic ketoacidosis $(\mathrm{pH}$ 6.91). Two weeks later, she presented with respiratory distress, and bilateral pulmonary emboli were demonstrated on computed tomography (CT) angiography. Her respiratory function improved within a week of commencement of anticoagulation therapy.

Two months after the initial presentation, the patient was hospitalised because of continuing weight loss reaching a nadir of $27.5 \mathrm{~kg}$ and vomiting, despite insulin therapy. Before any treatment, the serum sodium was $120 \mathrm{mmol} / \mathrm{l}$ (reference range, 135 to 145), potassium 1.9 $\mathrm{mmol} / \mathrm{l}$ (reference range, 3.2 to 4.5 ), chloride $75 \mathrm{mmol} / \mathrm{l}$ (reference range, 100 to 110 ), creatinine of $0.04 \mathrm{mmol} / \mathrm{l}$ (reference range, 0.05 to 0.1 ) and low blood glucose of $2.5 \mathrm{mmol} / \mathrm{l}$ (reference range, 3.0 to 7.8 ) and she had normal liver tests. A morning serum cortisol level was 915 $\mathrm{nmol} / \mathrm{l}$.

A $5.2 \times 3.6 \times 5 \mathrm{~cm}$ cystic right ovarian mass was 
detected. The patient developed persistent hypokalemia (as low as $1.8 \mathrm{mmol} / \mathrm{l}$ ) despite regular potassium replacement. A 24-h urinary free cortisol was elevated at $649 \mathrm{nmol} / 24 \mathrm{~h}$ (reference range < 150).

A total abdominal hysterectomy with the bilateral oophorectomy was performed and a benign serous cystic tumour was removed. The specimen was not stained for adrenocorticotropic hormone (ACTH). The patient required regular potassium replacement with eight tablets of potassium chloride $(8 \mathrm{mEq}) /$ day. She did not appear cushingoid. A repeat $24 \mathrm{~h}$ urinary free cortisol (UFC) was $1757 \mathrm{nmol} / 24 \mathrm{~h}$ (reference range < 150). The $1 \mathrm{mg}$ overnight dexamethasone test (DST) showed non suppression of the morning serum cortisol at $945 \mathrm{nmol} /$; confirmed on the $48 \mathrm{~h}$ low dose dexamethasone suppression test $(0.5 \mathrm{mg}$ gid) with the morning serum cortisol of $417 \mathrm{nmol} / \mathrm{l}$ at $1600 \mathrm{~h}$ on day 2. The ACTH level was measurable at $44 \mathrm{ng} / \mathrm{L}$ (reference range, 10 to 50 ). The $48 \mathrm{~h}$ high dose dexamethasone suppression test $(2$ $\mathrm{mg}$ qid) showed non suppression of the serum cortisol at $477 \mathrm{nmol} / \mathrm{l}(1600 \mathrm{~h}$, day 2) and $24 \mathrm{~h}$ UFC of $286 \mathrm{nmol} /$ day suggesting the diagnosis of the ectopic ACTH secretion. The CT of the chest, abdomen and pelvis showed no tumor. Magnetic resonance imaging (MRI) of the pituitary was normal.

Four months after initial presentation, the patient had no cushingoid appearance but she developed a marked proximal myopathy. Blood pressure was 140/80. The biochemistry showed persistent hypokalemia with serum potassium in the range of 2.8 to $3.2 \mathrm{mmol} / \mathrm{l}$ despite regular potassium replacement. Her urinary cortisol/ creatinine ratios were persistently elevated on consecutive early morning samples (median 205 $\mu \mathrm{mol} / \mathrm{mol}$ creatinine, range 47 to $303, \mathrm{n}=16$ ref. range $<$ 20).

Six months after initial presentation, the patient's clinical condition started to improve. Weight gradually increased to $49.5 \mathrm{~kg}$, the proximal myopathy resolved and her need for potassium supplements disappeared. The overnight DST showed appropriate serum cortisol suppression from 222 to $47 \mathrm{nmol} / \mathrm{l}(0800 \mathrm{~h})$; the $24 \mathrm{~h}$ UFC was within the normal range at $130 \mathrm{nmol} / 24 \mathrm{~h}$. A series of subsequent urinary cortisol/creatinine ratios were predominantly normal (median $19 \mu \mathrm{mol} / \mathrm{mol}$ creatinine, range 14 to $40, n=14$; reference range $<20$ ). She remains well with insulin treated diabetes ten years after initial presentation with a weight of $50 \mathrm{~kg}$.

\section{Case 2}

Three weeks after presenting obtunded with Staphylococcus aureus septicaemia and an extensive subdural empyema, a 74 years female, developed severe (190/90-205/105) hypertension despite treatment with maximal doses of four antihypertensive agents and new hypokalemia [2.2 to $3.1 \mathrm{mmol} / \mathrm{l}$ (reference range, 3.2 to 4.5)] simultaneously. Her hypertension was previously well controlled with amlodipine $5 \mathrm{mg}$ a day and quinapril $20 \mathrm{mg}$ a day. The renal function was normal, serum albumin was $21 \mathrm{~g} / \mathrm{L} 6$ (reference range, 33 to 47). She did not have cushingoid appearance. Her postoperative period was complicated by multiple pulmonary emboli and a prolonged pneumonia, which required intubation and mechanical ventilation for a one week period.

Her midnight serum cortisol was $381 \mathrm{nmol} / \mathrm{l}$. The $1 \mathrm{mg}$ overnight dexamethasone test showed non suppression of the morning $(0800 \mathrm{~h})$ serum cortisol of $798 \mathrm{nmol} / \mathrm{l}$, confirmed by $48 \mathrm{~h}$ dexamethasone at $0.5 \mathrm{mg} 6 \mathrm{~h}$ with raised serum cortisol of $427 \mathrm{nmol}(0800 \mathrm{~h})$. An overnight high dose $8 \mathrm{mg}$ dexamethasone test showed suppression of serum cortisol to $81 \mathrm{nmol} / \mathrm{l}$. The ACTH level was measurable at 14 to $34 \mathrm{ng} / \mathrm{L}$ (reference range, 10 to 50 ). The CT pulmonary angiogram also demonstrated a 2.5 $\mathrm{cm}$ left adrenal mass. Phaeochromocytoma and aldosterone secreting tumour were excluded.

An expectant course was followed. Four months after initial presentation, her BP settled to premorbid levels and need for potassium supplements disappeared. Twelve months later her $24 \mathrm{~h}$ urinary free cortisol was normal at $87 \mathrm{nmol} / 24 \mathrm{~h}$ (reference range <150). The overnight $1 \mathrm{mg}$ dexamethasone suppression test showed suppression of the morning cortisol to $35 \mathrm{nmol} / \mathrm{l}$, confirming the resolution of Cushing's syndrome. The CT adrenal showed no change in the size of the adrenal mass. The patient remains well four years after the episode.

\section{DISCUSSION}

The appearance of clinically evident Cushing's syndrome in response to acute illness is not a recognized phenomenon. Excess cortisol secretion was sought in both patients because of the appearance of marked hypokalemia in association with hypertension and/or proximal myopathy. The ACTH was measurable in both patients indicating an ACTH-dependent form of Cushing's syndrome.

The absence of obvious cushingoid phenotype in combination with prominent hypercortisolemia was consistent with a sudden development of the syndrome, suggestive of ectopic ACTH secretion. Both patients had otherwise unexplained severe hypokalemia (in one case associated with hypertension) suggesting saturation of the intracellular enzyme 11 beta hydroxysteroid dehydrogenase type 2 (11beta-HSD2), which inactivates cortisol to cortisone and activation of the mineralocorticoid receptor (Stewart and Krozowski, 1994). The development and persistence of the syndrome with demonstrable excess cortisol production weeks and months after the acute illness had settled and its spontaneous resolution is noteworthy.

An appropriate activation of the hypothalamic-pituitaryadrenal axis is seen in critical illness, and both high and low cortisol levels have been associated with increased 
mortality (Schuetz and Mueller, 2006; Hamrahian et al., 2004). The increases in cortisol are not usually associated with the clinically evident syndrome. The secretory activity of the hypothalamic-pituitary-adrenal (HPA) axis is maintained in the acute (hours to a few days) phase of critical illness. The hypercortisolism in this setting provides energy, protects the body and is reflected by increased glucogenesis, maintenance of intravascular volume and inhibition of the acute inflammatory reactions. However, when the disease becomes prolonged (lasting many days or weeks), there is a uniformly reduced pulsatile secretion of anterior pituitary hormones with active involvement of non-ACTH mediated pathways. In line with loss of hypothalamic ACTH control and decrease in plasma ACTH concentration, the diurnal variation in cortisol secretion disappears.

Both described subjects developed pulmonary emboli within two weeks of their initial presentation. Ectopic ACTH syndrome in majority of cases is caused by an intrathoracic neoplasm which secretes ACTH precursors (Stewart et al., 1989). Normal human lung produces small amount of the parent compound proopiomelanocortin (POMC) (White et al., 1990). It is believed that overexpression of gene responsible for POMC production in the setting of malignancy causes increase in POMC levels which is cleaved to ACTH and pro ACTH (Stewart et al., 1994), but the posttranslational processing of the peptides is unclear. Hypothetically pulmonary emboli might have incited a similar reaction which resulted in production of ACTH precursors by the lungs and has subsequently resolved as the process healed. Alternatively, an inflammatory reaction in the lungs due to pulmonary emboli could have caused secretion of inflammatory cytokines which can also stimulate the HPA axis (Chrousos, 1995). Alternately, transient Cushing's syndrome might have been related to suprapituitary stimulation of corticotrophs by corticotroph releasing hormone $(\mathrm{CRH})$ and vasopressin that was induced by illness through autonomic nervous system which modulates $\mathrm{CRH}$ secretion and represents the origin of a final common pathway for neurohormonal regulation of $\mathrm{ACTH}$-corticosterone release (Van Loon et al., 1989).
Most critically ill patients will usually have many reasons to explain potassium deficits, myopathy and even hypertension. The possibility that excess cortisol levels may be a contributory factor should be remembered in such patients. Interpreting cortisol levels in critically ill patients can be difficult and even substantial and non-suppressible elevations in cortisol may persist many weeks and possibly months after the acute illness has subsided. Clinicians should develop an awareness of this phenomenon, which may help them with the management of often very complex clinical presentations.

\section{REFERENCES}

Annane D, Sébille V, Troché G, Raphael JC, Gajdos P, Bellissant E (2000). A 3-level prognostic classification in septic shock based on cortisol levels and cortisol response to corticotrophin. JAMA, 283: 1038-1045.

Chrousos GP (1995). The hypothalamic-pituitary-adrenal axis and the immune-mediated inflammation. N. Engl. J. Med., 332: 1351-1362.

Frank W, Van den Berghe G (2004). Endocrine modifications and interventions during critical illness. Proc. Nutr. Soc., 63: 443-450.

Hamrahian AH, Oseni TS, Arafah BM (2004). Measurements of serum free cortisol in critically ill patients. N. Engl. J. Med., 350: 1629-1638

Schuetz P, Mueller B (2006). The hypothalamus-pituitary-adrenal axis in critical illness. In; Van den Berghe G, editor. Endocrinol. Metab. Clin. North Am., p. 35

Stewart MF, Crosby SR, Gibson S, Twentyman PR, White A (1989). Small cell lung cancer cell lines secrete predominantly ACTH precursor peptides not ACTH. Br. J. Cancer, 60: 20-24.

Stewart PM, Krozowski ZS (1999). 11 beta -hydroxysteroid dehydrogenase. Vitam Horm, 57: 249-324.

Stewart PM. Gibson S. Crosby SR, Penn R, Holder R, Ferry D, Thatcher N, Phillips P, London DR, White A (1994). ACTH precursors characterize the ectopic ACTH syndrome. Clin. Endocrinol. (Oxf), 40: 199-204.

Van den Berghe G, de Zegher F, Bouillon R (1998) Clinical review 95 Acute and prolonged critical illness as different neuroendocrine paradigms. J. Clin. Endocrinol. Metab., 83: 1827-1834.

Van Loon GR, Kvetnansky R, McCarty R, Axelrod J (1989). Stress: neurochemical and humoral mechanisms, vol. 1. New York: Gordon \& Breach Scientific Publishers, pp. 31-42.

White A, Clark AJ, Stewart MF (1990). The synthesis of ACTH and related peptides by tumours. Clin. Endocrinol. Metab., 4: 1-27. 